\section{Autochthonous Outbreak and Expansion of Canine Visceral Leishmaniasis, Uruguay}

\section{Dinora Satragno, ${ }^{1}$ Paula Faral-Tello, ${ }^{1}$ \\ Bruno Canneva, Lorenzo Verger, Alejandra Lozano, Edgardo Vitale, Gonzalo Greif, Carlos Soto, Carlos Robello, Yester Basmadjián}

Author affiliations: Universidad de la República, Montevideo, Uruguay (D. Satragno, B. Canneva, L. Verger, A. Lozano, E. Vitale, C. Soto, C. Robello, Y. Basmadjián); Instituto Pasteur, Montevideo (P. Faral-Tello, G. Greif, C. Robello)

\section{DOI: http://dx.doi.org/10.3201/eid2303.160377}

We report an outbreak of canine visceral leishmaniasis in Uruguay. Blood specimens from 11/45 dogs tested positive for Leishmania spp. Specimens of Lutzomyia longipalpis sand flies were captured; typing revealed Leishmania infantum. Our findings document an expansion of visceral leishmaniasis to southern South America and risk for vectorborne transmission to humans.

$\mathrm{V}$ isceral leishmaniasis (VL) is a zoonotic disease caused by flagellated protozoa of the genus Leishmania and transmitted by sand flies belonging to the Phlebotominae subfamily; those of the Lutzomia longipalpis species are the main vectors. VL affects humans and canids; canids are identified as the main reservoir of the parasite (1). This zoonosis has been endemic in northeastern Brazil for several centuries, but it has been recently expanding to southern areas of the South American continent (2-4). In 2010, the presence of the vector L. longipalpis sand flies was recorded for the first time in Uruguay (5); the right environmental conditions, the presence of competent sand fly vectors, and the constant appearance of new cases of canine and human leishmaniasis in border countries have made Uruguay susceptible to VL transmission (5).

In 2015, we performed a house-by-house survey in Arenitas Blancas $\left(31^{\circ} 25.000^{\prime} \mathrm{S}, 58^{\circ} 00.066^{\prime} \mathrm{W}\right)$ in Salto, Uruguay. We included 49 dogs in the survey. Wholeblood samples from $11(22 \%)$ tested positive for Leishmania spp. with 2 different diagnostic kits, TR DPP (BioManguinhos, Rio de Janeiro, Brazil) and Speed Leish K (Virbac, Carros, France), both of which detect antibodies raised against Leishmania antigens in whole blood, plasma, or serum by immunochromatographic methods. Among the dogs whose specimens tested positive, 8 showed the common clinical signs of skin lesions, fever, weight loss, and eye lesions; 3 were asymptomatic. Dogs

${ }^{1}$ These authors contributed equally to this article. whose specimens tested positive came from 9 different houses in the same neighborhood (Figure, panel A); of these, 2 dogs had never traveled outside their residence, and in 2 other cases, both dam and offspring were infected. Three dogs came from breeding kennels, and the rest were born in Arenitas Blancas.

We performed lymph node biopsies and bone marrow aspiration in dogs whose specimens tested positive; we also confirmed infection by direct observation of amastigotes in stained slide smears of aspirates. After extracting DNA from tissue samples by using the Quick-DNA Universal kit (Zymo Research, Irvine, California, USA), we performed PCR and sequencing of the ribosomal internal transcribed spacer 1 (6) to achieve typing of Leishmania spp. at the species level. We aligned and analyzed the sequences by using MAFFT software (7); the neighbor-joining phylogenetic tree obtained from the analysis showed that sequences identified from our samples group together with sequences belonging to $L$. infantum reference strains that we sequenced, as well as with sequences obtained from GenBank (Figure, panel B). Accession numbers and percentage of identity of the sequences obtained from GenBank are L. infantum, KM677146.1 and KC477100.1 (100\%); L. donovani, HM130608.1 and HQ830358.1 (99\%); L. amazonensis, DQ182536.1 (86\%); L. guyanensis, DQ182541.1 (81\%); and L. braziliensis, DQ182537.1 (81\%).

To verify that the complete domestic cycle of Leishmania spp. was taking place in the affected area, we placed CDC Miniature Light Traps (John W. Hock Company, Gainesville, FL, USA) in domiciles in which affected dogs had been found. All sampling was peridomestic and consisted of 13 traps placed overnight on 3 different nights; sampling resulted in collection of 3 sand flies, 1 male and 2 female. Using observational analysis, we identified the collected samples as L. longipalpis; this result was confirmed by PCR with species-specific primer LiCac $(8,9)$. Furthermore, we performed PCR amplification with Leishmaniaspecific primers AJS1 and DeB8 (8) using sand fly DNA as a template. A PCR product of $300 \mathrm{bp}$ from one of the sand flies was amplified and sequenced and showed Leishmania DNA in the vector (data not shown).

In summary, we describe an autochthonous outbreak of canine VL in Uruguay. The reported cases represent the expansion of VL to southern areas of the continent; the evidence shows that $L$. infantum is the parasite responsible for the outbreak in both canine hosts and a sand fly vector. The presence of competent vectors in the area constitutes a risk for the human population. Further work is needed to implement effective measures to control the extension of cases. It is also mandatory to improve surveillance of the vector and expand surveillance to other wild and domestic potential hosts. Finally, efforts should be made to prevent new cases of human VL in Uruguay. 

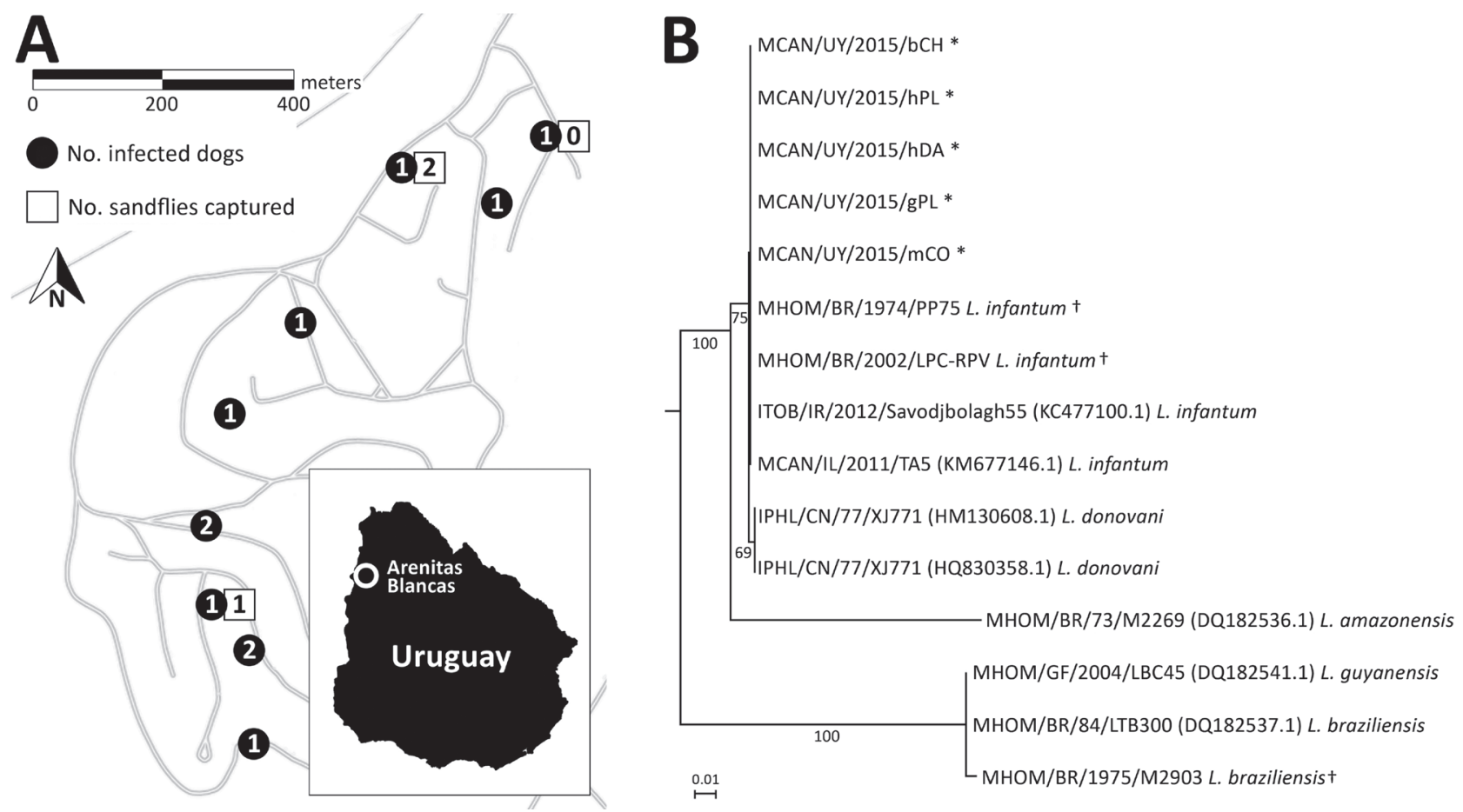

Figure. Survey of Leishmania spp. infection in dogs in Arenitas Blancas, Salto, Uruguay. A) Surveyed area in the locality of Arenitas Blancas in Salto, Uruguay. White squares represent the location of Lutzomia longipalpis sand fly captures, and black circles represent domiciles in which infected dogs were found; numbers indicate number of Leishmania spp.-infected sand flies or dogs at that location. B) Neighbor-joining phylogenetic tree obtained from the analysis of Leishmania internal transcribed spacer 1 sequences from tissue samples of infected dogs. Bootstrap values are represented at the nodes of major branches. Scale bar indicates nucleotide substitutions per site. *Sequences obtained from infected dog samples. †Reference strains sequenced by the authors.

\section{Acknowledgments}

We thank Victoria Barrios, Laura Odriozola, Pedro Martino, Marcelo Novoa, and Cirino Sequeira for their contribution to this work, and María Eugenia Francia (Institut Pasteur de Montevideo) for critically reading the manuscript.

This work was supported by Comisión Sectorial de Investigación Científica , Universidad de la República, Uruguay; Agencia Nacional de Investigación e Innovación (Uruguay) grant DCI-ALA/2011/023-502, "Contrato de apoyo a las políticas de innovación y cohesión territorial”; and Fondo para la Convergencia Estructural del Mercado Común del Sur (FOCEM) 03/11.

Dr. Satragno is a veterinarian in the laboratory of the Faculty's Veterinary Hospital of the Universidad de la República, Uruguay, and has extensive experience in the diagnosis of parasitic protozoa. Ms. Faral-Tello works at the Pasteur Institute in Montevideo and has extensive experience in molecular biology and parasite cultures.

\section{References}

1. Ashford DA, David JR, Freire M, David R, Sherlock I, Eulálio $\mathrm{MC}$, et al. Studies on control of visceral leishmaniasis: impact of dog control on canine and human visceral leishmaniasis in Jacobina, Bahia, Brazil. Am J Trop Med Hyg. 1998;59:53-7.
2. Barrio A, Parodi CM, Locatelli F, Mora MC, Basombrío MA, Korenaga M, et al. Leishmania infantum and human visceral leishmaniasis, Argentina. Emerg Infect Dis. 2012;18:354-5. http://dx.doi.org/10.3201/eid1802.110924

3. Gould IT, Perner MS, Santini MS, Saavedra SB, Bezzi G, Maglianese MI, et al. Visceral leishmaniasis in Argentina. Cases notification and distribution of vectors (2006-2012) [in Portuguese]. Medicina (B Aires). 2013;73:104-10.

4. Maia-Elkhoury AN, Alves WA, Sousa-Gomes ML, Sena JM, Luna EA. Visceral leishmaniasis in Brazil: trends and challenges. Cad Saude Publica. 2008;24:2941-7. http://dx.doi.org/10.1590/ S0102-311X2008001200024

5. Salomón OD, Basmajdian Y, Fernández MS, Santini MS. Lutzomyia longipalpis in Uruguay: the first report and the potential of visceral leishmaniasis transmission. Mem Inst Oswaldo Cruz. 2011;106:381-2. http://dx.doi.org/10.1590/S007402762011000300023

6. Schönian G, Nasereddin A, Dinse N, Schweynoch C, Schallig HD, Presber W, et al. PCR diagnosis and characterization of Leishmania in local and imported clinical samples. Diagn Microbiol Infect Dis. 2003;47:349-58. http://dx.doi.org/10.1016/S0732-8893(03)00093-2

7. Katoh K, Standley DM. MAFFT multiple sequence alignment software version 7: improvements in performance and usability. Mol Biol Evol. 2013;30:772-80. http://dx.doi.org/10.1093/molbev/ mst010

8. Smyth AJ, Ghosh A, Hassan MQ, Basu D, De Bruijn MH, Adhya S, et al. Rapid and sensitive detection of Leishmania kinetoplast DNA from spleen and blood samples of kala-azar patients. Parasitology. 1992;105:183-92. http://dx.doi.org/10.1017/S0031182000074096 
9. Lins RM, Oliveira SG, Souza NA, de Queiroz RG, Justiniano SC, Ward RD, et al. Molecular evolution of the cacophony IVS6 region in sandflies. Insect Mol Biol. 2002;11:117-22. http://dx.doi.org/10.1046/j.1365-2583.2002.00315.x

Addresses for correspondence: Carlos Robello, Unidad de Biología, Molecular Institut Pasteur de Montevideo, Mataojo 2020 CP11400, Montevideo, Uruguay; email: robello@pasteur.edu.uy; Yester Basmadjián, Departamento de Parasitología y Micología, Instituto de Higiene. Avda Alfredo Navarro 3051, CP 11600, Montevideo, Uruguay; email: yesterb@gmail.com

\section{Worldwide Endemicity of a Multidrug-Resistant Staphylococcus capitis Clone Involved in Neonatal Sepsis}

\author{
Marine Butin, Patricia Martins-Simões, \\ Jean-Philippe Rasigade, Jean-Charles Picaud, \\ Frédéric Laurent
}

\begin{abstract}
Author affiliations: Hospices Civils de Lyon, Lyon, France (M. Butin, P. Martins-Simões, J-P. Rasigade, J-C. Picaud, F. Laurent); INSERM, Lyon (M. Butin, P. Martins-Simões, J-P. Rasigade, F. Laurent); Claude Bernard University Lyon 1, Villeurbanne, France (J-P. Rasigade, J-C. Picaud, F. Laurent)

DOI: http://dx.doi.org/10.3201/eid2303.160833

A multidrug-resistant Staphylococcus capitis clone, NRCS$A$, has been isolated from neonatal intensive care units in 17 countries throughout the world. S. capitis NRCS-A prevalence is high in some neonatal intensive care units in France. These data highlight the worldwide endemicity and epidemiologic relevance of this multidrug-resistant, coagulase-negative staphylococci clone.
\end{abstract}

$\mathrm{P}$ reterm birth is the world's leading cause of death before 5 years of age (1). Neonatal sepsis, mostly due to coagulasenegative staphylococci, occurs frequently in neonatal intensive care units, especially in very low birthweight preterm infants (2). Cases and series of neonatal sepsis involving Staphylococcus capitis have been reported in different countries (3) and were initially considered unrelated epidemic bursts. More recently, we detected a single multidrug-resistant clone of $S$. capitis, designated as the NRCS-A clone and characterized by a specific pulsed-field gel electrophoresis (PFGE) pattern, in several neonatal intensive care units (NICUs) in France, Belgium, the United Kingdom, and Australia $(4,5)$. The clonality of the strains was confirmed by PFGE, multilocus sequence typing-like analysis, and whole-genome sequencing. We also showed that all NRCS-A isolates exhibited a decreased susceptibility to all of the antimicrobial agents frequently used in NICUs, namely $\beta$-lactams, aminoglycosides, and vancomycin (5). Furthermore, a recent study showed that $S$. capitis NRCSA-associated sepsis constitutes an independent risk factor for severe illness in neonates $(6)$.

We suspected that the initial report of NRCS-A dissemination in NICUs from 4 distant countries was only the tip of the iceberg and that the spread of NRCS-A strains was much wider than expected. To determine the extent of NRCS-A dissemination, we asked microbiologic laboratories worldwide to send us methicillin-resistant $S$. capitis strains isolated from blood cultures of neonates. These isolates were identified by matrix-assisted laser desorption/ionization time-of-flight mass spectrometry and subjected to PFGE using the SmaI restriction enzyme as previously described (7). NRCS-A's characteristic PFGE pattern was found for 154 strains isolated between 1994 and 2015 in 34 NICUs from 17 countries: Australia, Belgium, Brazil, Canada, Czech Republic, Denmark, Finland, France, Germany, the Netherlands, New Zealand, Norway, South Korea, Switzerland, Taiwan, the United Kingdom, and the United States.

Retrospective, laboratory-based epidemiologic investigations to estimate the prevalence of NRCS-A strains in NICUs could not be performed on the same worldwide scale, so we conducted such a study in France. Results collected from 47 of the 57 NICUs in France during 2014 indicated that only 4 NICUs were free of NRCS-A. In the 43 other NICUs, NRCS-A strains accounted for up to $46 \%$ of all cases of positive cultures of blood from neonates (median 13\%, interquartile range $10 \%-20 \%$ ) and represented $19 \%$ of all coagulase-negative staphylococci strains isolated from the blood cultures of neonates.

Taken together, these data unquestionably demonstrate the unusual worldwide endemicity of the multidrug-resistant NRCS-A clone in NICUs. In addition, the epidemiologic data from France highlight the propensity of NRCS-A to invade and settle in most NICUs on a national scale. Once endemic in a NICU, NRCS-A strains expose infected neonates to a risk of therapeutic failure because treatment of neonatal sepsis involving methicillin-resistant coagulase-negative staphylococci is usually based on vancomycin and aminoglycosides, to which NRCS-A isolates are not susceptible (3-5).

A thorough investigation of the determinants of the worldwide spread of NRCS-A is urgently needed to unravel the dissemination routes and reservoirs of this multidrugresistant clone and to succeed in managing and controlling its diffusion. The risk of vancomycin treatment failure warrants an investigation of alternate antimicrobial stewardship strategies, in particular linezolid, daptomycin, and ceftarolin, to treat NRCS-A-associated neonatal sepsis. 